\title{
Erratum to: Hotspots Assessment of Spatial Water Losses in the Off-Farm Open Channels Irrigation Supply System
}

Muhammad Nadeem Asghar • Mahmood Ali Khan •
Bryson Lashbrook • Timo Zumkley • Scott Lawson

Published online: 11 June 2011

(C) Springer Science+Business Media B.V. 2011

\section{Erratum to: Water Resour Manage (2011) 25:1281-1297 DOI 10.1007/s11269-010-9744-3}

The article is withdrawn as it was submitted by mistake of the senior author who was not in a position to submit and to transfer copyright on the content to Springer.

The online version of the original article can be found at http://dx.doi.org/10.1007/s11269-010-9744-3.

M. N. Asghar $(\varangle) \cdot$ M. A. Khan · B. Lashbrook · T. Zumkley International Centre of Water for Food Security, Charles Sturt University, Locked Bag 588, Building 24, Wagga Wagga, NSW, 2678, Australia

e-mail: nasghar@csu.edu.au

M. N. Asghar

Cooperative Research Centre for Irrigation Futures, P.O. Box 56, Darling Heights,

Toowoomba, QLD 4350, Australia

T. Zumkley

Westfalian Wilhelms-University Muenster, Robert-Koch-Strasse 26-28,

48149, Muenster, Germany

S. Lawson

GHD, Suite 3, Level 1, 161-169 Baylis Street, Wagga Wagga, NSW, 2650, Australia 